Copyright (C 2004* SAE International. This paper is posted on this site with permission from SAE International. Further use or distribution of this paper is not permitted without permission from SAE" 
2004-32-0099 / 20044386

\title{
Pre-evaporated Stratified Injection
}

\author{
Chris Tyree, Holger Roser and John Dartnall \\ University of Technology, Sydney, Australia
}

Copyright (C) 2004 SAE International and Copyright (C) 2004 Society of Automotive Engineers of Japan, Inc.

\begin{abstract}
Pre-evaporated Stratified Injection (PSI) is a low-cost mechanical fuel injection system which dramatically reduces exhaust gas emissions in small $1 C$ engines. In two-stroke engines, this is achieved by incorporating a mechanically driven coaxial air-fuel injector within the upper half of an engine's main piston. In four stroke engines the injector cylinder is located in the cylinder head with the injector piston driven by the valve cam. In both configurations, the relative motion of the injector piston draws a rich air-fuel mixture from the carburetor, captures and compresses for sufficient time under most operating conditions to substantially evaporate fuel before direct injection into the cylinder.
\end{abstract}

This technology allows for stratified charge combustion without wall wetting (spray impingement), leading to lower hydrocarbon $(\mathrm{HC})$ and carbon monoxide $(\mathrm{CO})$ emissions in four-stroke engines, and for the first time allowing low cost, small two-stroke engines to meet nonhandheld emission standards.

\section{INTRODUCTION}

The current state of worldwide legislation would indicate a combined hydrocarbon $(\mathrm{HC})$ plus oxides of nitrogen (NOx) ceiling of $8 \mathrm{~g} / \mathrm{kWh}$ and carbon monoxide limits of $549 \mathrm{~g} / \mathrm{kWh}$ by 2010 , with some regions demanding this level by 2007 [1]. To meet these new emission standards, the California Air Resources Board (CARB) recommends manufacturers employ catalysts and secondary air injection, adding further expense to OHV four-stroke engines [1].

PSI can position a pre-evaporated air-fuel mixture within the cylinder such that combustion is enhanced to a level where catalysts and secondary air injection are not required on OHV four-strokes in order to easily meet the new emission standards. The PSI technology allows small two-stroke engines to meet the new standards, as the pre-evaporated air-fuel charge can be injected after the exhaust port has closed. eliminating short-circuit losses and thus over $90 \%$ of two-stroke emissions [2] unstable combustion and misfiring are other main contributors to high levels of two-stroke $\mathrm{HC}$ and $\mathrm{CO}$, and accurate placement of a PSI charge also minimizes this.
As two-stroke engines generally have low levels of NOX emissions as a result of intrinsic exhaust gas recirculation (EGR) and lower combustion temperatures, with PSI the two-stroke cycle potentially offers emission advantages over the four-stoke cycle.

In either the two or four-stroke configuration, the modifications required to small engines in current manufacture are minimal. The design and performance of the PSI system in its two-stroke four cycle configuration, in conjunction with CFD simulation and testing data, is presented in the following sections.

\section{PSI TECHNOLOGY}

Historically DI systems have been classified into two general categories, single-fluid type (fuel only) and dualfluid type (mixture of air and fuel) injection. High pressure single-fluid type DI systems have been in production for automotive applications for some time, but the cost and complexity of reducing injected fuel particles to a size small enough to substantially avoid wall wetting have prevented their introduction into the small engine market.

Dual-fluid DI systems use pressurized air to enhance fuel atomization with relatively low injection pressures. The Orbital Engine Company introduced an electronically controlled air-assist direct injection system for applications such as motorcycle and marine engines [3]. Furthermore, Piaggio developed the FAST (Fully Atomized Stratified Turbulence) system comprising a separate piston-compressor assembly to deliver the airfuel mixture into the combustion chamber [4].

PSI technology represents a simple low-cost alternative to the DI systems outlined above. The PSI injection system comprises an injector piston which is located coaxially within the main piston and may be mechanically actuated by means such as a secondary connecting rod linked to an offset crankpin, or the pivoting motion of the main connection rod, as sketched in Figure 1.

As the injector piston moves downwards, a rich air-fuel mixture enters the injection chamber via a duct and is compressed (typically $250 \mathrm{kPa}$ ) prior to injection into the 

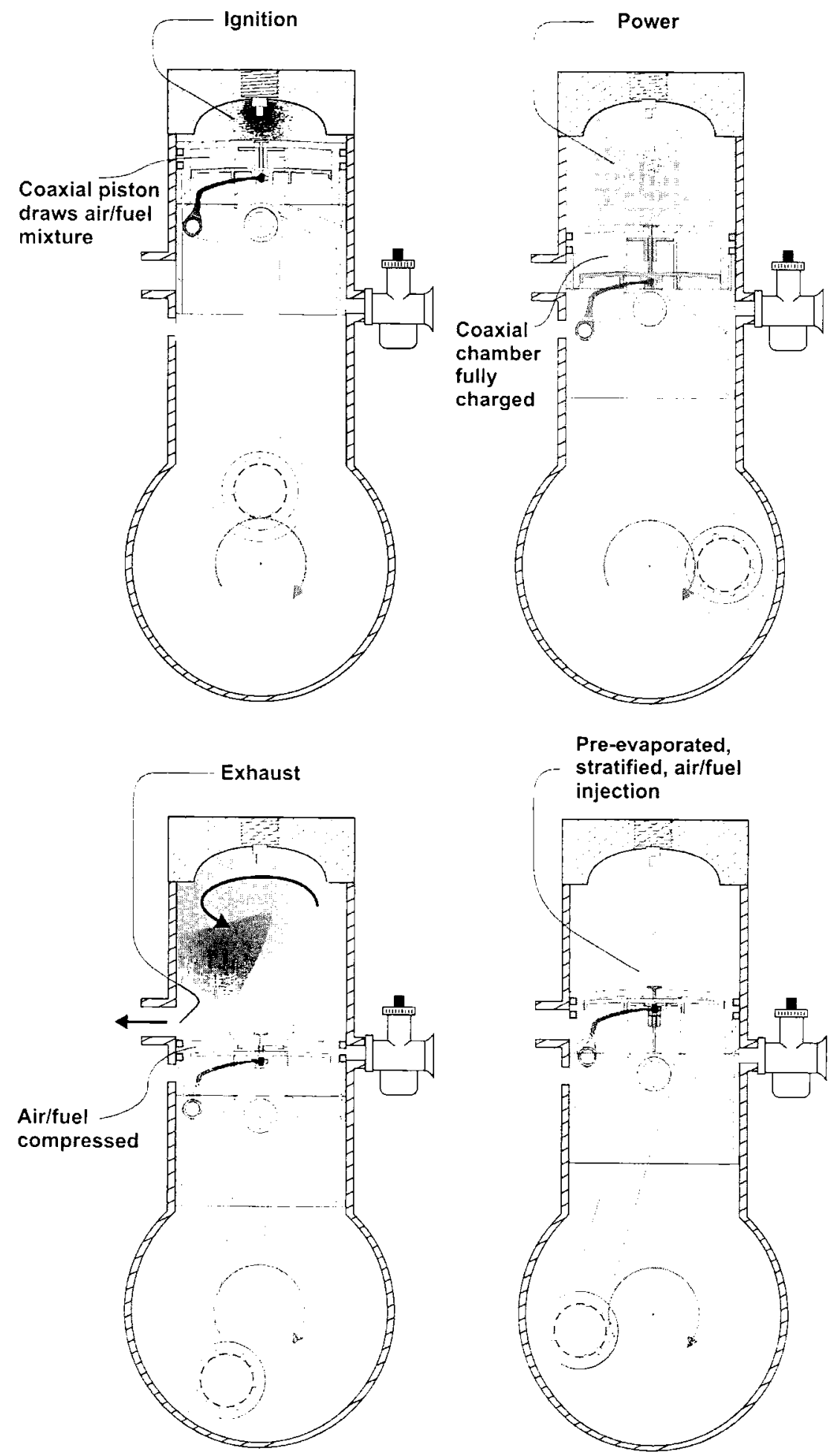

Pre-evaporated, - stratified, air/fuel injection

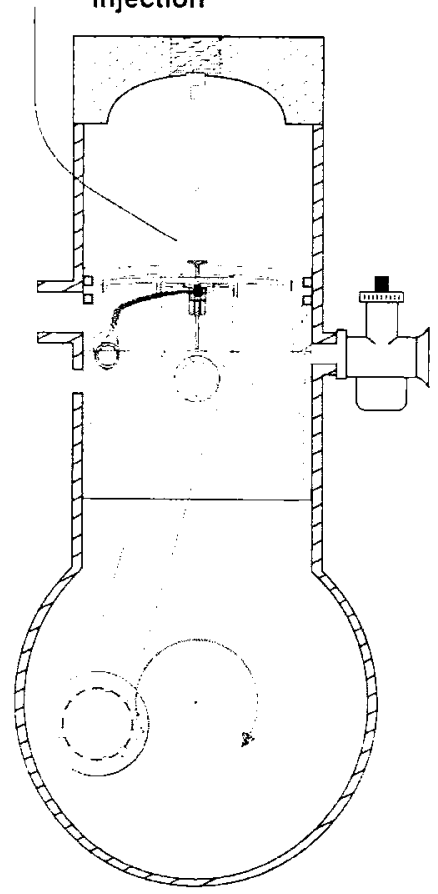

Figure 1: One PSI application - two-stroke power from four-cycle operation 
combustion chamber through a valve located in the piston crown. As the injection event occurs after completion of the scavenging process (after the exhaust port has closed), charge losses through short-circuiting of the two-stroke cycle are eliminated. This mechanism effectively separates the fuel charging process from the scavenging process and increases the engine's specific power output through supercharging.

Engine speed and load can be varied by adjusting the air-fuel mixture which may be generated by simple carburetor technology. Modification to the carburetor involves reducing the venturi throat sufficiently to obtain an air-fuel mixture in the vicinity of 3:1. The primary air stream into the crankcase can remain un-throttled.

Apart from simplicity, the main difference to other DI systems is evaporation of the fuel prior to the injection event. This enables a rich air-fuel cloud to be positioned around the spark plug to promote stratified charge combustion. Thus, flame quenching effects in dilute mixture areas can be avoided, as a significant factor for increased emissions due to unstable combustion at idle and light load operation. Initial testing has indicated that the improved combustion efficiency allows two-strokes to achieve better engine performance and lower fuel consumption than standard overhead valve (OHV) fourstroke engines.

The advantages of the PSI technology compared to other direct injected two-stroke systems and optimized OHV four-stroke technology are many. As can be seen from the following summary, it becomes difficult to separate the technical from the commercial:

- $\mathrm{HC}+\mathrm{NOx}$ emissions less than $8 \mathrm{~g} / \mathrm{kWh}$

- Inexpensive uncomplicated technology

- Reduced packaging size (downsizing)

- Consistent mixture preparation through duel stage metering

- Stable low load combustion through fuel stratification

- Increased compression ratio possible due to reduced knocking tendency

- Reduction of pumping losses through un-throttled crankcase induction

\section{INJECTION PROCESS}

Although DI is generally accepted as the most effective way to enhance the combustion process, injecting fuel particles small enough to allow for complete evaporation before combustion generates a conflict between fuel droplet size and injection penetration as illustrated in Figure 2 [5]. A finely atomized fuel cloud is always desirable, since large fuel droplets enhance unwanted wall wetting (a main shortcoming with conventional DI systems) and localized non-homogenous air-fuel mixtures.
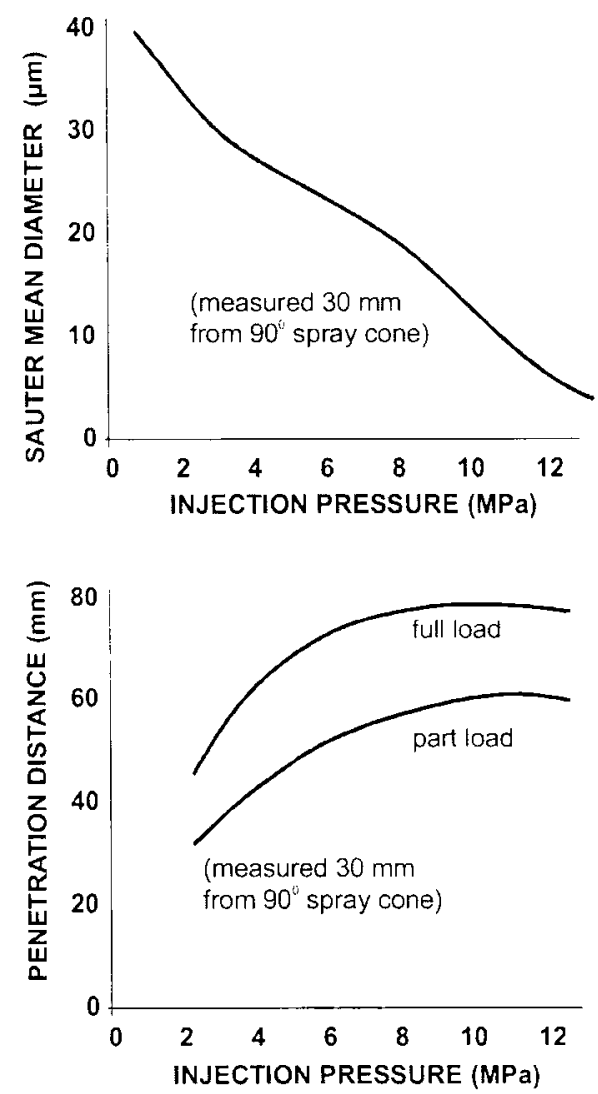

Figure 2: Conflict between fuel particle size and penetration distance [5]

Even at the relatively slow speed of $3,000 \mathrm{rpm}$, the available time for the fuel to evaporate is less than $5 \mathrm{~ms}$. This sets a maximum fuel particle SMD (Sauter Mean Diameter) of around $7 \mu \mathrm{m}$, which typically requires injection pressures in excess of $12 \mathrm{MPa}$. However, such high pressures generate long spray patterns and lead to surface wetting, pockets of steep air-fuel ratio gradients and unstable air flow distribution, all of which contribute to degraded combustion and increased emissions. Multiple burst injection reduces injection penetration, but in a turbulent environment it also means more fuel is dispersed, so a stoichiometric mixture in the spark plug zone just before ignition time, at every speed and condition, is very difficult to achieve.

Injecting air with the fuel lowers the fuel droplet size significantly, and low pressure air-fuel injection can achieve fuel particles as small as $7 \mu \mathrm{m}$ SMD, which is small enough to evaporate sufficiently for low emission combustion (see Figure 3). Small engines fitted with the Orbital Engine Company's air-assist fuel injectors for example, readily achieve $\mathrm{HC}+\mathrm{NOx}$ emissions as low as $12 \mathrm{~g} / \mathrm{kWh}$. At around $0.6 \mathrm{MPa}$, the injector pressure is significantly lower than single-fluid type DI systems, the injected plume is shorter and there is less surface wetting [3]. 
A third alternative, one not actively pursued until now, is to pre-evaporate the fuel prior to injection. If the air-fue mixture is captured within the injector chamber under the hot piston crown over one engine cycle, there is sufficient time and heat for almost complete evaporation, even at higher engine speeds. And because the fuel is pre-evaporated, surface wetting in the confined space of a small engine ceases to be an issue.

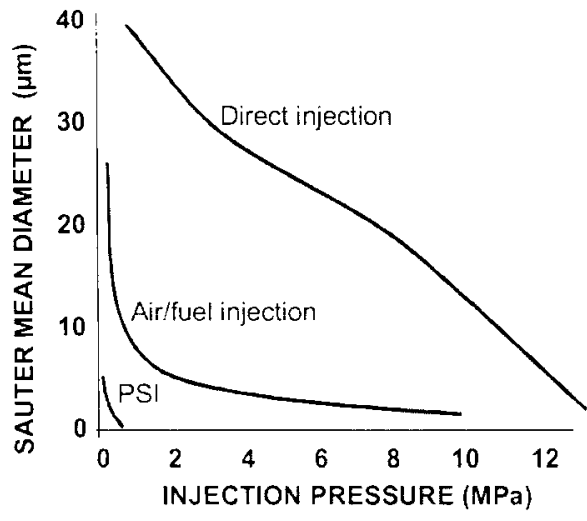

Figure 3: Comparison of PSI fuel droplet size to alternative systems

As illustrated in Figure 3, SMD values of PSI are substantially below other air-fuel injection systems for the same injection pressure. Not only does this take wall wetting out of contention, but because the PSI jet is directed towards the location of the spark plug, a wide tolerance is available for the placement of a stratified airfuel charge in the vicinity of the spark plug at ignition time at various loads and speeds.

The amount of fuel injected is accurately metered in a two stage process. Firstly, preparation of the rich mixture with a typical ratio in between $2: 1$ and $3: 1$ in a reduced venturi throat carburetor, and secondly, injection of a pre-determined amount of air-fuel mixture into the cylinder. Thereby, a more accurate air-fuel mix can be obtained than through a traditional single stage carburetion process - and equally apparent combining a pre-mixed charge with air in the cylinder will provide better mixing than direct injection.

In addition, the PSI technology increases the air-fuel change by up to $25 \%$. This supercharging provides extra oxygen at the vicinity of the spark plug when high levels of EGR are used to improve fuel economy and reduce NOX.

Figure 4 shows the sequential distribution of the injected air-fuel cloud. The dynamic flow-field has been simulated by means of computational fluid dynamics (CFD) using CFX solver code.

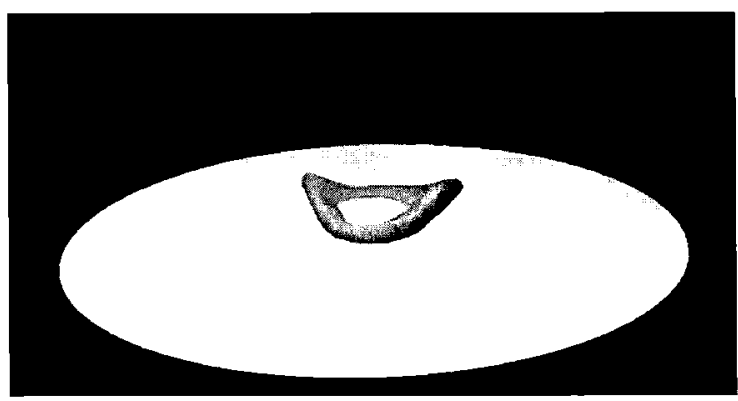

$125 \mathrm{deg}$. BTDC

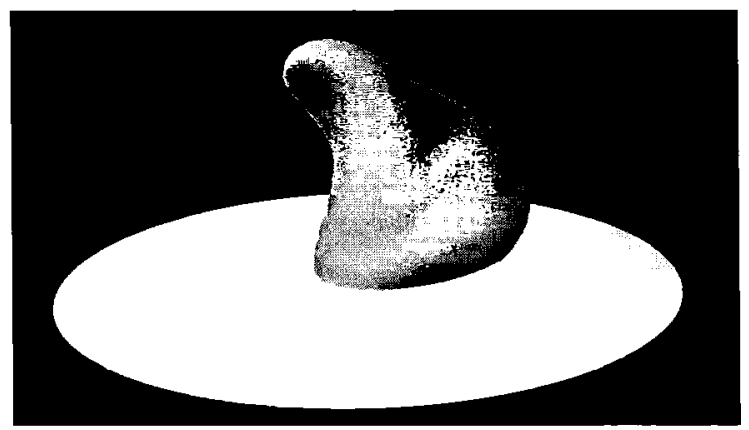

90 deg. BTOC

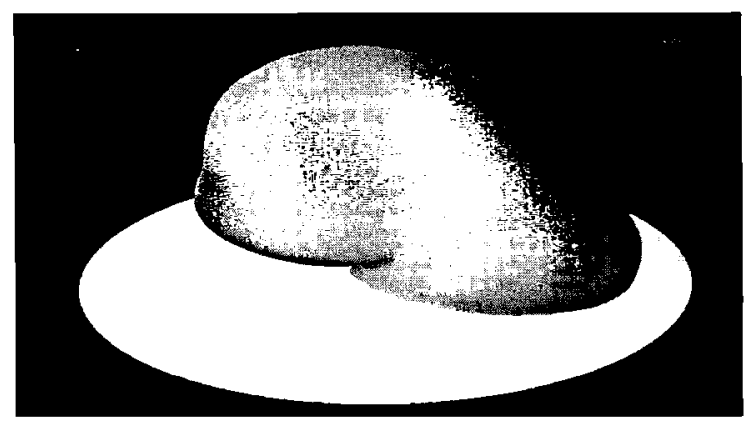

$60 \mathrm{deg}$. BTDC

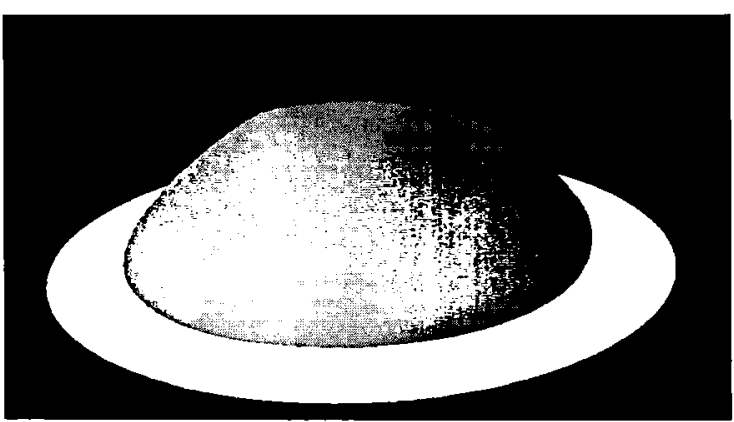

25 deg. $3 \pi D C$

Figure 4: CFD simulation of air-fuel cloud distribution at $3000 \mathrm{rpm}$ and full load (air-fuel ratio within fuel cloud is $20: 1$ or richer) 
Table 1 lists some key parameters which influence the in-cylinder mixture formation process and means of control.

Table1: Parameters affecting in-cylinder mixture formation

\begin{tabular}{|l|l|}
\hline Parameter & Means of control \\
\hline $\begin{array}{l}\text { Fuel amount } \\
\text { injected } \\
\text { (engine load) }\end{array}$ & $\begin{array}{l}\text { Variation of injection pressure and } \\
\text { flow rate by throttling charge flow } \\
\text { entering injector. }\end{array}$ \\
\hline $\begin{array}{l}\text { Spray pattern } \\
\text { and penetration }\end{array}$ & $\begin{array}{l}\text { Variation of injection pressure by } \\
\text { throttling of charge flow. } \\
\text { Adjustment of injection timing. }\end{array}$ \\
\hline $\begin{array}{l}\text { Fuel } \\
\text { stratification }\end{array}$ & $\begin{array}{l}\text { Variation of injection pressure. } \\
\text { Adjustment of injection timing. } \\
\text { Regulation of scavenging flow field }\end{array}$ \\
\hline
\end{tabular}

\section{SCAVENGING PROCESS}

Although two-stroke PSI provides satisfactory results with standard transfer port configurations, modifications to the standard geometry are required to achieve optimized variable fuel gradient stratification. In addition, if the main intake air stream entering the crankcase is not throttled, the cylinder contains a full charge of air and a typical EGR of $15 \%$ across all loads and speeds. After air-fuel injection, at low loads this equates to a centrally stoichiometric but global air-fuel mixture as lean as 50:1.

Indeed, stratification of the cylinder charge in a twostroke configuration is mandatory if low emission levels are to be realized. This in turn necessitates a residual swirl flow-field (rotation about the cylinder axis) after scavenging, as injection through residual tumble at low loads disrupts the stratification.

CFD modeling has uncovered several port configurations that allow scavenging efficiencies of up to $90 \%$ while at the same time producing a residual swirl motion within the cylinder. The preferred configuration provides a variable angle cyclonic swirl with a vortex in which to inject the rich air-fuel mixture at low loads (see Figure 5), and at full loads enough angular turbulence to attain a homogenous charge (see Figure 6).

When pre-evaporated fuel is injected into a variable angle cyclonic swirl, a surprisingly robust stratification at different loads and speeds can be achieved. Primarily this is because at lower throttle settings the pressure differential valve in the top of the piston delays the airfuel injection until the cyclonic swirl is almost parallel with the piston top, so the global air-fuel mixture becomes more stratified.

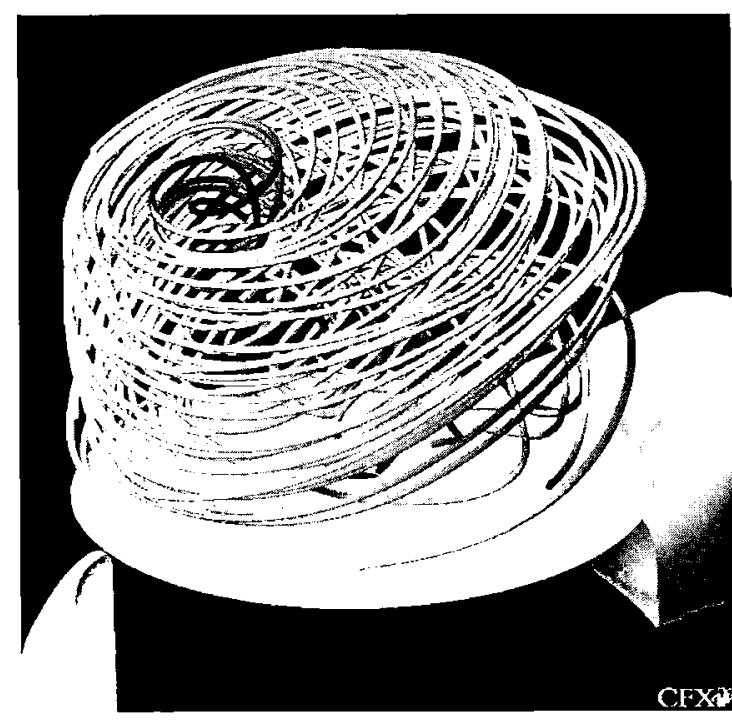

Figure 5: Residual swit motion when injection commences at $3000 \mathrm{rpm}$ and $30 \%$ load

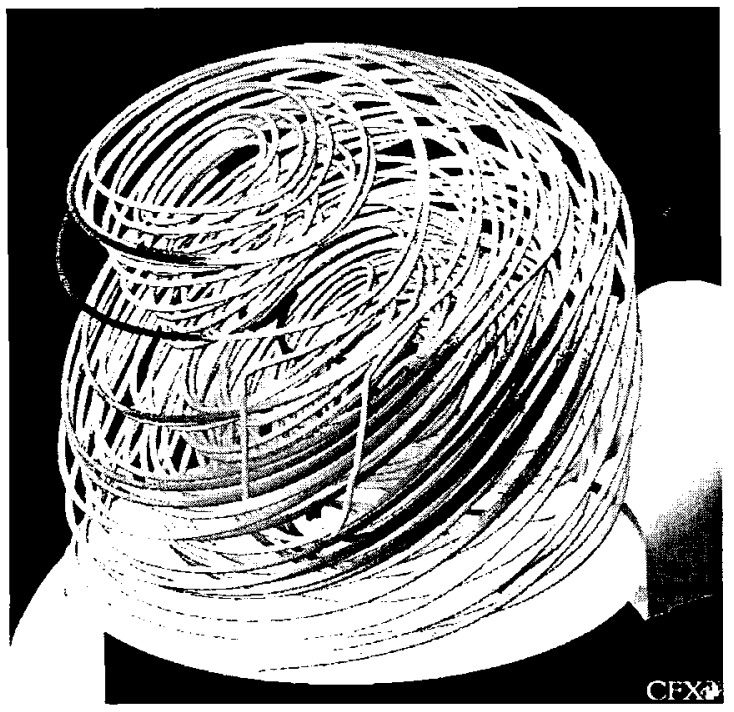

Figure 6: Residual swir motion when injection commences at $3000 \mathrm{rpm}$ and full load

\section{SYSTEM PERFORMANCE AND EMISSIONS}

Subsequent to CFD modeling, empirical testing has been undertaken with a standard Honda GCV $160(160$ $\mathrm{cm}^{3}$ ) four-stroke and an off the shelf $160 \mathrm{~cm}^{3}$ two-stroke engine made in Australia by Victa Lawncare Pty Ltd. Implementation of the PSI system into the Victa twostroke engine involved replacing the piston and minor modifications to the cylinder porting. Key specifications of the test engine are given in Table 2. Preliminary testing has demonstrated that both $\mathrm{HC}+\mathrm{NOX}$ and $\mathrm{CO}$ emissions exceed the target standards. 
Table2: Test engine specifications

\begin{tabular}{|l|l|}
\hline \multicolumn{2}{|l|}{ Test Engine Specifications } \\
\hline Engine Type & 2-stroke Victa VSX 160 \\
\hline $\begin{array}{l}\text { Displacement } \\
\text { Volume }\end{array}$ & $160 \mathrm{~cm}^{3}$ \\
\hline Bore $\times$ Stroke & $61.5 \times 54 \mathrm{~mm}$ \\
\hline $\begin{array}{l}\text { Compression } \\
\text { Ratio }\end{array}$ & $7.5: 1$ \\
\hline Rated Power & $2.6 \mathrm{~kW} @ 3000 \mathrm{rpm}$ \\
\hline Max. Torque & $9 \mathrm{Nm} @ 1600 \mathrm{rpm}$ \\
\hline Ignition Timing & $22 \mathrm{deg}$. BTDC \\
\hline $\begin{array}{l}\text { Exhaust Port } \\
\text { Open/Close }\end{array}$ & $118 \mathrm{deg}$. ATDC/BTDC \\
\hline $\begin{array}{l}\text { Transfer Port } \\
\text { Open/Close }\end{array}$ & 130 deg. ATDC/BTDC \\
\hline $\begin{array}{l}\text { Combustion } \\
\text { Chamber }\end{array}$ & Dome shape \\
\hline Test Fuel & Unleaded petrol RON 92 \\
\hline $\begin{array}{l}\text { Lubrication Oil } \\
\text { Valvoline advanced synthetic } \\
\text { fortified formula oil }\end{array}$ \\
\hline $\begin{array}{l}\text { Lubrication } \\
\text { Type }\end{array}$ & Directed oil-mist lubrication \\
\hline
\end{tabular}

Tests were carried out at UTS using a TEC PAC II five gas analyzer supplied by Autodiagnostic Systems P/L and an electrical dynamometer and other equipment constructed at UTS in Sydney. The Victa PSI engine is shown attached to the test rig below.

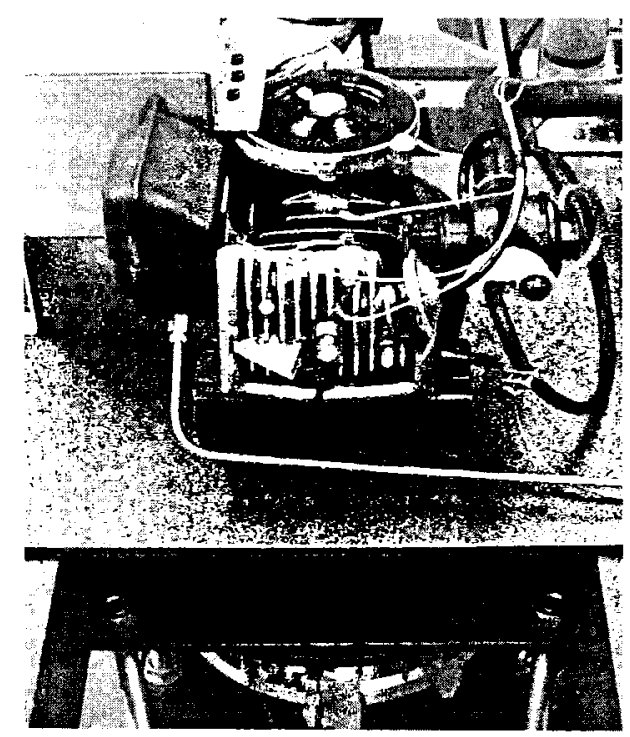

Figure 7: Victa engine with PSI piston on the UTS test rig
Test results from a PSI piston in an otherwise unmodified two-stroke engine confirm that injecting after the exhaust port has closed reduces $\mathrm{HC}$ emissions from over $250 \mathrm{~g} / \mathrm{kWh}$ down to $28 \mathrm{~g} / \mathrm{kWh}$ (as measured to Directive 2002/88/EC of the European Parliament) primarily due to the elimination of short circuit losses.

Removing oil from the petrol and adopting a directed oil lubrication system, as well as improvements to the carburetor, reduced emissions to $12.9 \mathrm{~g} / \mathrm{kWh}$ - to a level comparable with a well manufactured OHV four-stroke engine. Modifications to the port configuration and tuning the PS| timing reduced raw as measured emissions to $7.2 \mathrm{~g} / \mathrm{kWh}$.

$\mathrm{HC}+\mathrm{NO}$ Emissions ( $\mathrm{g} / \mathrm{kWh})$

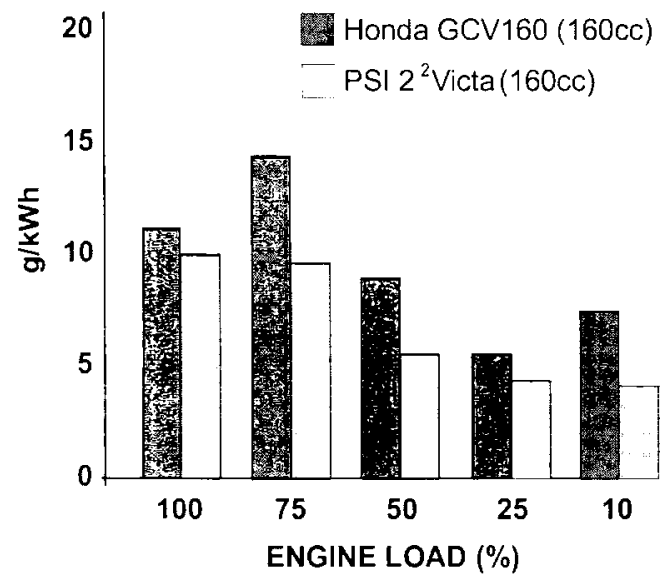

Figure 8: PSI and OHV four-stroke emissions

This low figure can be attributed to several factors, although at this stage we have been unable to satisfactorily quantify each of these.

- Intrinsic EGR

- Almost total fuel evaporation prior to injection

- Stratification of the air-fuel mixture

- Placement of the fuel cloud to minimize flame quenching in dilute mixtures at low loads

- Increased compression ratio due to supercharging

- Injection away from piston crevice volumes

- Absence of four-stroke valve crevice volumes

- Increased efficiency at low loads through eliminating $\mathrm{OHV}$-train friction

\section{LUBRICATION}

As two-stroke PSI engines scavenge with pure air and not an air-fuel-oil mixture, a supplementary lubrication system is required. The test engine employed a directed mist of flow limited oil onto the piston components and cylinder walls. The oil was atomised by the initial sonic airflow into the crankcase air inlet. Eliminating the need for lubrication in the lower regions of the crankcase required the use of sealed pre-greased bearings. 
Preliminary testing indicates that a 1,000 hour operating life can be achieved with fuel to oil ratios approaching $700: 1$, primarily because oil can be delivered where it is needed, and because once there it is not dissolved by the fuel. In the Victa engine this equates to a half liter container of oil lasting for 500 operating hours, which means under average circumstances a single container will last for around 10 years.

\section{CONCLUSION}

The PSI technology offers small engine manufacturers a highly competitive emissions solution. Fuel losses during scavenging in traditional two-stroke engines are eliminated, the specific fuel consumption is reduced and the specific power output increased through supercharging. Moreover, typical two-stroke high power to weight ratios, torque advantages and simplicity over four-stroke engines are maintained.

A non-conventional port arrangement enables the formation of a residual swirl flow-field after scavenging, so that stratification of the atomized fuel cloud can be achieved by injecting into the center of the cycionic vortex. This allows stable stratified charge combustion of total air-fuel mixtures up to 50:1 at idle and part load operating conditions.

Given that currently available air-fuel injection systems can easily achieve $\mathrm{HC}+\mathrm{NOx}$ emissions of less than 12 $\mathrm{g} / \mathrm{kWh}$, it is apparent that PSI technology in its well developed state can easily and consistently achieve significantly lower values. As this is accomplished without electronics and additional appliances such as air compressors, fuel pumps, or solenoid injectors, it is also apparent that PSI offers lower servicing and manufacturing costs.

In conjunction with a product cost analysis, the above results demonstrate that the PSI technology can be incorporated within an engine's piston to meet future stringent emission requirements without a catalyst. This emission level is superior to an optimized OHV fourstroke in the same engine class, and is achieved in minimalist form incorporating mature technologies which require only minimal development cost.

Future research, in conjunction with as yet to be selected licensees, will be directed towards more detailed performance and life tests to optimize both combustion and scavenging processes over a broader range of engine configurations, particularly motorcycles. It is anticipated that a detailed empirical analysis of port and injection timing and geometries will allow $\mathrm{HC}+\mathrm{NOX}$ emissions to be reduced to negligible levels.

\section{ACKNOWLEDGMENTS}

We would like to thank the project team at the University of Technology, Sydney and TyTeam Pty Ltd for their support and contribution in completing this research.
In addition, we wish to thank the special workshop and technical personnel at UTS and TAFE for their highly valued assistance in constructing and testing of the prototype engine.

\section{REFERENCES}

1. California Environmental Protection Agency Air Resources Board, Initial Statement of Reasons for Proposed Rulemaking Public Hearing to Consider the Adoption of Exhaust and Evaporative Emission Control Requirements for Small Off-Road Equipment and Engines Less than or Equal to 19 Kilowatts, California, 2003

2. Heywood, J. B., Sher, E., "The Two-Stroke Cycle Engine: Its Development, Operation, and Design", Taylor \& Francis, Warrendale, PA, 1999

3. Website: www. orbeng.com.au/orbital/orbitalTechnol ogy/combustProcess_lowpressure.htm

4. M. Nuti, et al, "FAST Injection System: A Very Simple Way to Lean Combustion in SI Engines", SETC Paper, Small Engine Technology Conference, 1997

5. Adapted from Stan C, "Particulars of Combustion in Direct Injection Spark Ignition Engines", SAE paper 2001-01-0249, pp 3-4.

\section{CONTACT}

Chris Tyree or Holger Roser

University of Technology, Sydney

Faculty of Engineering

PO Box 123, Broadway

NSW 2007

Australia

Phone: +6129922 4212

Fax: $\quad+61299222646$

Email: cwt@bigpond.net.au

Or visit the PSI website:

www.psiengine.com.au

\section{DEFINITIONS, ACRONYMS, ABBREVIATIONS}

ATDC: After top dead center

BDC: Bottom dead center

BTDC: Before top dead center

CFD: Computational fluid dynamics

CO: Carbon monoxide

DI: Direct injection

EGR: Exhaust gas recirculation

FAST: Fully atomized stratified turbulence

HC: Hydrocarbons

IC: Internal combustion

NOx: Oxides of nitrogen

OHV: Overhead valve

PSI: Pre-evaporated Stratified Injection

SMD: Sauter mean diameter

TCD: Top dead center

UTS: University of Technology Sydney 